\title{
Effects of position on non-stress test results and maternal satisfaction
}

\author{
Salime Mucuk ${ }^{A-F}$, Tülay Bülbü̈ ${ }^{B, E, F}$ \\ Department of Nursing, Division of Obstetrics and Gynecology Nursing, Faculty of Health Sciences, Erciyes University, Kayseri, Turkey \\ A - research concept and design; $B$ - collection and/or assembly of data; $C$ - data analysis and interpretation; \\ $D$ - writing the article; $E$ - critical revision of the article; $F$ - final approval of the article
}

Address for correspondence

Salime Mucuk

E-mail: mucuksIm@gmail.com

Funding sources

None declared

Conflict of interest

None declared

Received on April 10, 2021

Reviewed on April 26, 2021

Accepted on July 13, 2021

Published online on September 9, 2021

Cite as

Mucuk S, Bülbül T. Effects of position on non-stress test results and maternal satisfaction. Adv Clin Exp Med. 2021;30(11):1127-1132. doi:10.17219/acem/ 140196

DOI

10.17219/acem/140196

Copyright

Copyright by Author(s)

This is an article distributed under the terms of the

Creative Commons Attribution 3.0 Unported (CC BY 3.0)

(https://creativecommons.org/licenses/by/3.0/)

\begin{abstract}
Background. The non-stress test (NST) is a simple non-invasive procedure commonly used in obstetrics clinics to assess fetal health. It is important that mothers feel comfortable during the NST and that the test results are obtained quickly.

Objectives. To determine the effects of maternal position on NST results and participants' satisfaction during the procedure.

Materials and methods. This was a randomized controlled experimental study conducted at the Department of Obstetrics and Gynecology Polyclinic of Erciyes University Hospital (Kayseri, Turkey) between October 2017 and March 2018. During the NST, either the supine, semi-Fowler or left lateral position was utilized. Questionnaire forms and NST tracings were collected from 275 participating mothers and analyzed. The $x^{2}$ test was used to determine whether the distribution of categorical variables differed between groups. The Kruskal-Wallis test was used to determine whether median scores differed between groups. A p-value $<0.05$ was considered statistically significant.

Results. Most participants in the left lateral (78.9\%) and semi-Fowler positions (88.4\%) reported feeling satisfied compared to only $24.2 \%$ of participants in the supine position $(p<0.001)$. Participants also felt more comfortable in the left lateral (92.2\%) and semi-Fowler positions (87.2\%). In the supine position, most participants (68.7\%) reported experiencing back pain $(p<0.001)$. There were no significant differences among groups in terms of basal heart rate $(p=0.497)$, reactivity time $(p=0.421)$ or percentage of reactivity $(p=0.676)$. The number of accelerations was 5.0 in the left lateral position, 4.5 in the semi-Fowler position and 4.0 in the supine position $(p=0.051)$.
\end{abstract}

Conclusions. Our findings support the use of the semi-Fowler and left lateral positions during the NST. Participants reported high satisfaction in these positions and felt more comfortable, and no procedurerelated problems occurred.

Key words: non-stress test, maternal position, maternal satisfaction 


\section{Background}

The non-stress test (NST) is used to interpret changes in fetal heart rate (FHR) in relation to fetal body movements during the antenatal period. It is a commonly used method to assess antenatal fetal health, provide a timely diagnosis and prevent complications that may occur due to intrauterine asphyxia. ${ }^{1-4}$

Maternal position during the NST is an important factor for reducing procedure-related problems. At our clinic, nurses typically put mothers in a supine position because it allows for easy administration of the NST. However, in this position, venous return and cardiac output may decrease, particularly due to the pressure caused by the enlarged uterus upon the inferior vena cava, and supine hypotensive syndrome may occur. Furthermore, decreased uteroplacental circulation and fetal oxygenation may negatively affect NST results. Thus, the lateral recumbent, semi-Fowler or sitting positions may be more acceptable positions for the NST to avoid inducing supine hypotension or maternal discomfort, such as a backache. ${ }^{1,5-13}$ In addition, it is important that mothers feel comfortable with the position they take during the NST because it lasts on average $20-40 \mathrm{~min}$. During the procedure, most mothers complain of a backache caused by the supine position and boredom from being in the same position. Since the position during the NST should be comfortable and satisfactory for the mothers, identifying the effect of different positions on test results and maternal satisfaction will aid in improving the NST procedure.

\section{Objectives}

In the literature, there are limited studies on the effect of maternal position on NST results and mothers' satisfaction. Thus, the current study aimed to address these research gaps.

\section{Materials and methods}

\section{Study population}

This was a randomized controlled experimental study conducted in the Department of Obstetrics and Gynecology, Polyclinic at Erciyes University Hospital (Kayseri, Turkey) between October 2017 and March 2018. Pregnant women who attended the polyclinic for prenatal exams were included in this study.

The required sample size was calculated using the NCSSPASS software (NCSS LLC, East Kaysville, USA). Based on the study by Nathan et al., the number of women needed for each group was determined $(\alpha=0.05$, power $=0.80)$ to be at least $50 .{ }^{14}$ However, 100 participants were assigned to each group due to the possibility that mothers might want to change position during the procedure, withdraw from the study or for some other reason. The study inclusion criteria were as follows: patients at 32 to 42 gestational weeks, who did eat at least $2 \mathrm{~h}$ before the test, and did not use alcohol or cigarettes before the test, not taking any barbiturate derivative medicine, able to communicate verbally, and consented to participate in the study. Participants with complications of pregnancy such as hypertension, diabetes, intrauterine growth restriction, or fetal anomalies were excluded. Participants who met the inclusion criteria were assigned to 1 of the 3 maternal positions during the antepartum NST according to a computerized randomization list.

\section{Measurements}

Data were collected from questionnaires and NST tracings. The questionnaire included socio-demographic information, obstetric characteristics, vital signs, and satisfaction with the allocated position. The satisfaction questions concerned feeling any discomfort during the NST procedure, satisfaction with the position and position preference. Heart rate, systolic and diastolic blood pressure (SBP and $\mathrm{DBP})$, and respiration rate were recorded as well.

An external electronic fetal monitor (Hewlett Packard Series 50A; Hewlett-Packard GmbH, Böblingen, Germany) was used to measure FHR and uterine activity in each study participant. The bedside monitor unit received information about the FHR and uterine activity from sensors or transducers, processed the information, and provided output in the form of a numeric display and a printed strip.

\section{Procedure}

Pregnant women who attended the polyclinic for prenatal exams were included in this study. Participants were informed about the aim of the study and those who met the inclusion criteria were randomly assigned to 1 of the 3 maternal positions (supine, semi-Fowler or left lateral) during the antepartum NST. The NST for each participant took the average of $20 \mathrm{~min}$. All tests were carried out between 9:00 AM and 12.00 PM. The mother's vital signs were measured after resting for 5-10 min. Reactivity time and rate, basal speed, and the number of accelerations and decelerations were recorded from the NST strips after testing concluded.

\section{Statistical analyses}

Statistical analyses were performed using IBM SPSS Statistics v. 26 (IBM Corp., Armonk, USA). Descriptive statistics were given as the number (n), percent $(\%)$, median $(M), 1^{\text {st }}$ quartile $(\mathrm{Q} 1)$, and $3^{\text {rd }}$ quartile $(\mathrm{Q} 3)$. The distribution of numerical data was evaluated using the Shapiro-Wilk normality test. Comparisons of numerical variables between groups were performed using the Kruskal-Wallis test. The Fisher's exact test was used to compare categorical variables. ${ }^{15}$ If there was a significant difference in the $\chi^{2}$ test, 
randomized $(n=300)$ supine $(\mathbf{n}=\mathbf{1 0 0})$

1 missing or incorrect data left lateral $(n=100)$

3 not participating in the study 4 NST strip was not readable 3 missing or incorrect data
semi-Fowler $(\mathbf{n}=\mathbf{1 0 0})$

4 not participating in the study 5 NST strip was not readable 5 missing or incorrect data

$$
\text { analyzed }(\mathrm{n}=99)
$$

analyzed $(\mathrm{n}=90)$

Fig. 1. Study flowchart

the differences between the groups in the categories were determined using the Bonferroni-corrected 2 proportion Ztest. A p-value $<0.05$ was considered statistically significant.

A complete study flowchart is presented as Fig. 1.

\section{Ethical approval}

This study was approved by the Ethics Committee of Erciyes University (approval No. 2013/427). All patients were informed about the purpose of the study and provided written and oral consent. The Declaration of Helsinki was complied with at all stages of the study.

\section{Results}

As shown in Table 1, the experimental groups were similar to each other in terms of mean age $(p=0.738)$, height $(p=0.095)$, weight $(p=0.425)$, number of pregnancies $(p=0.767)$, gestational age $(p=0.844)$, heart rate $(p=0.127)$, $\operatorname{SBP}(p=0.310), \operatorname{DBP}(p=0.416)$, respiration rate $(p=0.623)$, and education level $(\mathrm{p}=0.545)$. There was no statistically significant difference among the groups in terms of basal heart rate $(p=0.497)$. The number of accelerations was 5.0 in the left lateral position, 4.5 in the semi-Fowler position and 4.0 in the supine position ( $p=0.051)$. No significant differences were found in terms of reactivity time $(\mathrm{p}=0.421)$, reactivity rate $(\mathrm{p}=0.676)$ or percentage of deceleration ( $\mathrm{p}=0.748$ ) among the 3 groups (Table 2$)$.

Most participants in the left lateral (78.9\%) and semiFowler positions $(88.4 \%)$ reported being satisfied. Only $24.2 \%$ of participants were satisfied in the supine position and $53.5 \%$ reported dissatisfaction with this position ( $\mathrm{p}<0.001$ ), with $71.7 \%$ reporting discomfort. In contrast, discomfort was reported by only $7.8 \%$ of participants in the left lateral position and $12.8 \%$ in the semi-Fowler position ( $\mathrm{p}<0.001)$. In the supine position, most participants $(68.7 \%)$ reported back pain $(\mathrm{p}<0.001)$. Most participants

Table 1. Comparison of participant characteristics by position

\begin{tabular}{|c|c|c|c|c|c|}
\hline \multirow{2}{*}{ Participant characteristics } & \multirow{2}{*}{$\begin{array}{l}\text { Supine } \\
n=99\end{array}$} & \multirow{2}{*}{$\begin{array}{l}\text { Left lateral } \\
\qquad n=90\end{array}$} & \multirow{2}{*}{$\begin{array}{c}\text { Semi-Fowler } \\
n=86\end{array}$} & \multicolumn{2}{|c|}{ Test statistics } \\
\hline & & & & $H / X^{2}$ & $p$-value \\
\hline \multicolumn{6}{|c|}{ Continuous variables, $M\left(Q_{1}-Q_{3}\right)$} \\
\hline Age [years] & $27.0(24.0-33.0)$ & $28.5(24.8-33.0)$ & $28.0(23.0-33.0)$ & 0.606 & 0.738 \\
\hline Height $[\mathrm{cm}]$ & $160.0(158.0-165.0)$ & $160.0(156.8-165.0)$ & $162.5(158.0-167.0)$ & 4.716 & 0.095 \\
\hline Weight [kg] & $78.0(70.0-87.0)$ & $76.5(69.8-86.0)$ & $74.0(68.0-85.0)$ & 1.711 & 0.425 \\
\hline Pregnancies [number] & $3.0(2.0-4.0)$ & $3.0(1.0-3.0)$ & $3.0(2.0-4.0)$ & 0.530 & 0.767 \\
\hline Gestational age [weeks] & $38.0(37.0-39.0)$ & $38.0(37.0-39.0)$ & $38.0(37-39)$ & 0.339 & 0.844 \\
\hline Heart rate [beats/min] & $92.0(80.0-100.0)$ & $87.0(80.0-94.5)$ & $88.0(80.0-96.5)$ & 4.126 & 0.127 \\
\hline $\mathrm{SBP}[\mathrm{mm} \mathrm{Hg}]$ & $120.0(110.0-120.0)$ & $117.5(100.0-120.0)$ & $120.0(110.0-120.0)$ & 2.343 & 0.310 \\
\hline $\mathrm{DBP}[\mathrm{mm} \mathrm{Hg}]$ & $70.0(70.0-80.0)$ & $70.0(60.0-80.0)$ & $70.0(60.0-80.0)$ & 1.754 & 0.416 \\
\hline Respiration rate [rate/min] & $22.0(20.0-24.0)$ & $22.0(20.0-24.0)$ & $22.0(20.0-24.0)$ & 0.948 & 0.623 \\
\hline \multicolumn{6}{|c|}{ Categorical variables, n (\%) } \\
\hline $\begin{array}{l}\text { Education } \\
\text { primary school } \\
\text { secondary school } \\
\text { high school } \\
\text { university }\end{array}$ & $\begin{array}{l}39(39.4) \\
27(27.3) \\
22(22.2) \\
11(11.1)\end{array}$ & $\begin{array}{l}39(43.3) \\
18(20.0) \\
21(23.3) \\
12(13.3)\end{array}$ & $\begin{array}{l}34(39.5) \\
28(32.6) \\
15(17.4) \\
9(10.5)\end{array}$ & 6.998 & 0.545 \\
\hline
\end{tabular}

n - number of participants; \% - column percentages; $\mathrm{M}$ - median; $\mathrm{Q}_{1}-1^{\text {st }}$ quartile; $\mathrm{Q}_{3}$ - $3^{\text {rd }}$ quartile; SBP - systolic blood pressure; DBP - diastolic blood pressure; $\mathrm{H}$ - Kruskal-Wallis test; $\mathrm{X}^{2}-\mathrm{X}^{2}$ test. 
Table 2. Comparison of non-stress test features in each group

\begin{tabular}{|c|c|c|c|c|c|}
\hline \multirow{2}{*}{ Non-stress test features } & \multirow{2}{*}{$\begin{array}{l}\text { Supine } \\
n=99\end{array}$} & \multirow{2}{*}{$\begin{array}{l}\text { Left lateral } \\
\qquad \mathrm{n}=90\end{array}$} & \multirow{2}{*}{$\begin{array}{c}\text { Semi-Fowler } \\
n=86\end{array}$} & \multicolumn{2}{|c|}{ Test statistics } \\
\hline & & & & $H / X^{2}$ & $p$-value \\
\hline \multicolumn{6}{|c|}{ Continuous variables, $M\left(Q_{1}-Q_{3}\right)$} \\
\hline Reactivity time [min] & $8.0(5.0-12.0)$ & $7.0(5.0-10.0)$ & $7.0(5.0-10.0)$ & 1.730 & 0.421 \\
\hline Basal heart rate [beats] & $139.0(130.0-140.0)$ & $135.0(130.0-140.0)$ & $135.0(130.0-140.0)$ & 1.398 & 0.497 \\
\hline Acceleration [number] & $4.0(2.0-6.0)$ & $5.0(4.0-8.0)$ & $4.5(3.0-7.0)$ & 5.941 & 0.051 \\
\hline \multicolumn{6}{|c|}{ Categorical variables, n (\%) } \\
\hline $\begin{array}{l}\text { Reactivity } \\
\text { reactive } \\
\text { nonreactive }\end{array}$ & $\begin{array}{l}85(85.8) \\
14(14.2)\end{array}$ & $\begin{array}{l}81(90.0) \\
9(10.0)\end{array}$ & $\begin{array}{l}76(88.4) \\
10(11.6)\end{array}$ & 0.782 & 0.676 \\
\hline $\begin{array}{l}\text { Deceleration } \\
\text { none } \\
1 \\
2 \\
3\end{array}$ & $\begin{array}{c}92(92.9) \\
5(5.1) \\
1(1.0) \\
1(1.0)\end{array}$ & $\begin{array}{c}84(93.3) \\
5(5.6) \\
0(0.0) \\
1(1.1)\end{array}$ & $\begin{array}{c}84(97.7) \\
2(2.3) \\
0(0.0) \\
0(0.0)\end{array}$ & 4.044 & 0.748 \\
\hline
\end{tabular}

$\mathrm{n}$ - number of participants; \% - column percentages; $\mathrm{M}$ - median; $\mathrm{Q}_{1}-1^{\text {st }}$ quartile; $\mathrm{Q}_{3}-3^{\text {rd }}$ quartile; $H$ - Kruskal-Wallis test; $X^{2}-X^{2}$ test.

Table 3. Distribution of satisfaction with position in each group

\begin{tabular}{|c|c|c|c|c|c|c|c|c|}
\hline \multirow{2}{*}{$\begin{array}{c}\text { Characteristics } \\
n(\%)\end{array}$} & \multirow{2}{*}{$\begin{array}{l}\text { Supine } \\
n=99\end{array}$} & \multirow{2}{*}{$\begin{array}{l}\text { Left lateral } \\
\qquad n=90\end{array}$} & \multirow{2}{*}{$\begin{array}{l}\text { Semi-Fowler } \\
n=86\end{array}$} & \multicolumn{2}{|c|}{ Test statistics } & \multicolumn{3}{|c|}{ Pairwise comparisons* } \\
\hline & & & & $x^{2}$ & $\mathrm{p}$-value & $\begin{array}{l}\text { supine \& } \\
\text { left lateral }\end{array}$ & $\begin{array}{c}\text { supine \& } \\
\text { semi-Fowler }\end{array}$ & $\begin{array}{l}\text { left lateral \& } \\
\text { semi-Fowler }\end{array}$ \\
\hline \multicolumn{9}{|c|}{ Satisfaction } \\
\hline satisfied & $24(24.2)^{\mathrm{a}}$ & $71(78.9)^{b}$ & $76(88.4)^{b}$ & \multirow{3}{*}{113.436} & \multirow{3}{*}{$<0.001$} & $<0.001$ & $<0.001$ & 0.106 \\
\hline not satisfied & $53(53.5)^{\mathrm{a}}$ & $3(3.3)^{b}$ & $5(5.8)^{b}$ & & & $<0.001$ & $<0.001$ & 0.489 \\
\hline partially satisfied & $22(22.2)^{\mathrm{a}}$ & $16(17.8)^{\mathrm{a}}$ & $5(5.8)^{b}$ & & & 0.473 & 0.002 & 0.019 \\
\hline \multicolumn{9}{|c|}{ Discomfort during the process } \\
\hline yes & $71(71.7)^{\mathrm{a}}$ & $7(7.8)^{b}$ & $11(12.8)^{b}$ & \multirow{2}{*}{109.947} & \multirow{2}{*}{$<0.001$} & $<0.001$ & $<0.001$ & 0.325 \\
\hline no & $28(28.3)^{\mathrm{a}}$ & $83(92.2)^{b}$ & $75(87.2)^{b}$ & & & $<0.001$ & $<0.001$ & 0.325 \\
\hline \multicolumn{9}{|c|}{ Disturbance type } \\
\hline none & $28(28.3)^{\mathrm{a}}$ & $83(92.2)^{b}$ & $76(88.4)^{b}$ & \multirow{3}{*}{112.948} & \multirow{3}{*}{$<0.001$} & $<0.001$ & $<0.001$ & 0.450 \\
\hline back pain & $68(68.7)^{\mathrm{a}}$ & $7(7.8)^{\mathrm{b}}$ & $10(11.6)^{b}$ & & & $<0.001$ & $<0.001$ & 0.450 \\
\hline respiratory distress & $3(3.0)^{\mathrm{a}}$ & $0(0.0)^{\mathrm{a}}$ & $0(0.0)^{\mathrm{a}}$ & & & 0.248 & 0.250 & - \\
\hline \multicolumn{9}{|c|}{ Preferred position } \\
\hline right lateral recumbent & $16(16.2)^{\mathrm{a}}$ & $5(5.6)^{a b}$ & $2(2.3)^{b}$ & \multirow{5}{*}{110.524} & \multirow{5}{*}{$<0.001$} & 0.052 & 0.002 & 0.444 \\
\hline left lateral recumbent & $20(20.2)^{a}$ & $33(36.7)^{b}$ & $2(2.3)^{c}$ & & & 0.015 & $<0.001$ & $<0.001$ \\
\hline supine & $22(22.2)^{\mathrm{a}}$ & $7(7.8)^{b}$ & $6(7.0)^{b}$ & & & 0.008 & 0.004 & 0.999 \\
\hline semi-Fowler & $16(16.2)^{\mathrm{a}}$ & $15(16.7)^{\mathrm{a}}$ & $63(73.3)^{b}$ & & & 0.999 & $<0.001$ & $<0.001$ \\
\hline right/left lateral recumbent & $25(25.2)^{\mathrm{ab}}$ & $30(33.3)^{b}$ & $13(15.1)^{\mathrm{a}}$ & & & 0.263 & 0.102 & 0.005 \\
\hline
\end{tabular}

$\mathrm{n}$ - number of participants; \% - column percentages; $X^{2}-\chi^{2}$ test; * significance values for 2 proportion Z-test with Bonferroni correction; ${ }^{a}$,,$c$ the same superscript letters indicate no statistically significant difference between the position groups in each rows; \&-compared to.

in the semi-Fowler position (73.3\%) reported that they would prefer to be in the same position for the next NST (Table 3).

\section{Discussion}

This study was conducted to determine the effects of maternal position on NST results and mothers' satisfaction with the procedure. There were no statistically significant differences among our groups in terms of basal
FHR or maternal heart rate. The reason for the similar results across groups may be that only healthy pregnancies were included to control for risky situations in this study. The number of accelerations was 5.0, 4.5, and 4.0 in the left lateral, semi-Fowler and supine position, respectively. Similar results were obtained by Cito et al., who found that maternal positions (reclining, sitting, walking) did not result in statistically significant differences in baseline FHR or the number of large accelerations. ${ }^{1}$ In a study by Ibrahim et al., using the same positions (left lateral, semi-Fowler and supine) as our study, a higher baseline 
FHR and increased number of accelerations were found in the left lateral position, followed by the semi-Fowler position, compared to the supine position. ${ }^{16}$ The results obtained by Ibrahim et al. are very similar to ours.

Furthermore, there was no statistically significant difference between the groups in terms of reactivity time in our study, which is consistent with other studies in the literature. A study comparing 4 different positions (sitting-up, semi-Fowler, left lateral, and supine) determined that reactivity time was not significantly different among the groups.?

The reactivity rate did not differ significantly among the groups in the current study. In the literature, different results have been obtained in studies comparing different positions during the NST. In a study using the same positions as our study, similar results were obtained: the NST reactivity rate did not show statistically significant differences between the left lateral, semi-Fowler and supine positions. ${ }^{16}$ A study comparing the sitting-up, semi-Fowler and semi-Fowler left lateral positions also reported no significant differences between groups in terms of reactive NST rate. ${ }^{17}$ Similar results were obtained in a study in which the left lateral and sitting positions were examined, and the reactivity rate was not significantly different between the groups. ${ }^{18}$ However, Nathan et al. ${ }^{14}$ found that the nonreactive NST rate in the supine position was higher than in the sitting position. In a study comparing the effect of 4 different positions (supine, left lateral, semi-Fowler, and sitting-up), the lowest reactive NST rate was noted in the supine position. ${ }^{7}$ Another study reported a positive correlation between maternal and fetal parameters in the left lateral position compared to other positions during the NST. ${ }^{19}$

Maternal satisfaction and comfort during different obstetrical procedures is a fundamental issue for perinatal nursing care. Importantly, maternal comfort, satisfaction and collaboration during the NST may affect the NST results. Thus, this study aimed to assess maternal perceptions of comfortable positions during the antenatal NST. Our results indicated that most of the women in the semi-Fowler position and the left lateral position were satisfied with these positions, while the satisfaction rate was significantly lower for women in the supine position. Furthermore, the rate of women who reported discomfort in the supine position was higher than those in other positions. Specifically, women in the supine position complained of backaches. The back pain may be experienced due to the pressure caused by the enlarged uterus over the lumbosacral region when in the supine position. When women were asked which position they would prefer to take during the NST procedure, most preferred the semi-Fowler position. Based on these findings, the semi-Fowler position and the left lateral position may be more suitable for the NST procedure.

The findings of this study are similar to those of other studies in that the majority of antenatal mothers were reportedly comfortable in the left lateral position. Kaur and
Saha stated that around $67 \%$ of participants reported being comfortable in the left lateral position during the NST, whereas only $25 \%$ of participants supported the sitting position. ${ }^{18}$ Essa and Hafez reported that the semi-Fowler and left lateral positions were associated with lower levels of discomfort than the supine position. ${ }^{12}$ Another study reported that both maternal fatigue and back pain were reduced in the semi-Fowler position compared to the left lateral position. ${ }^{20} \mathrm{El}$ Sayed and Mohamady also noted that nearly $2 / 3$ of participants felt uncomfortable in the supine position compared to the semi-Fowler and left lateral positions. ${ }^{21}$ A study investigating the comfort of mothers during antenatal NST procedures reported that the comfort level was higher in the semi-Fowler position than in the supine position. ${ }^{22}$ Similar results were obtained in other studies. ${ }^{8,9}$ The results of the current study and other studies in the literature seem congruent with physiological changes during pregnancy.

\section{Limitations}

The most important limitation of this study is the small sample size, as some variables such as the number of accelerations were very close to the statistical significance level, but did not reach the statistical significance.

\section{Conclusions}

Our findings support that the semi-Fowler and left lateral positions are more suitable for the NST. The satisfaction and comfort of mothers in these positions were high and no disturbances such as a backache occurred.

\section{ORCID iDs}

Salime Mucuk (D) https://orcid.org/0000-0003-4787-7515

Tülay Bülbül (D) https://orcid.org/0000-0001-5166-0074

\section{References}

1. Cito G, Luisi S, Mezzesimi A, Cavicchioli C, Calonaci G, Petraglia F. Maternal position during non-stress test and fetal heart rate patterns. Acta Obstet Gynecol Scand. 2005;84(4):335-338. doi:10.1111/j.00016349.2005.00644.x

2. Alp Dal N, Ertem G. Evaluation of fetal health. In: Sevil Ü, Ertem G, eds. Perinatology and Care. Ankara, Turkey: Nobel Medical Bookstores; 2016:383-386.

3. Umana OD, Siccardi MA. Prenatal non-stress test. StatPearls Publishing; 2020. http://www.ncbi.nlm.nih.gov/pubmed/30725808. Updated August 10, 2020. Accessed December 19, 2020.

4. Nazari S, Hatami E, Tabatabayeechehr M, Bagheri M, Ghorbani M. Diagnostic value of non-stress test interpreted by smart interpretive software. J Midwifery Reprod Health. 2018;6(3):1384-1389. doi: 10.22038/jmrh.2018.21461.1228

5. Humphries A, Mirjalili SA, Tarr GP, Thompson JMD, Stone P. The effect of supine positioning on maternal hemodynamics during late pregnancy. J Matern Fetal Neonatal Med. 2019;32(23):3923-3930. doi:10. 1080/14767058.2018.1478958

6. POGP. Goog Practice Statement:Supine lying during pregnancy.J Pelvic Obstet Gynaecol Physiother. 2018;122:77-83. https://pogp.csp.org. uk/sites/default/files/journal/2018-08/15_14301043.pdf/. Accessed December 20, 2020. 
7. Aluş $M$, Okumuş $H$, Mete $S$, Güçlü $S$. The effects of different maternal positions on non-stress test: An experimental study. J Clin Nurs. 2007; 16(3):562-568. doi:10.1111/j.1365-2702.2006.01570.x

8. Abdallah EL Sayed H, Hassan Mohamady S. Effects of different maternal positions during non-stress test on maternofetal physiological parameters. Tanta Sci Nurs J. 2016;10(1):116-131. doi:10.21608/tsnj. 2016.71197

9. Sekhavat $\mathrm{L}$, Tabatabaei A. The effect of different maternal position on non-stress test (NST). World App/ Sci J. 2014;32(5):853-856. doi:10. 5829/idosi.wasj.2014.32.05.83246

10. Samuel R, Karkada S, Fernandes S, Bhat P. Materno foetal physiological parameters in sitting and left lateral position during non-stress test (NST monitoring in pregnancy: A cross over study). Manipal J Nurs Heal Sci. 2015;1(2):83-86. http://eprints.manipal.edu/ id/eprint/146821/. Accessed December 17, 2020.

11. Khatib N, Weiner Z, Beloosesky R, Vitner D, Thaler I. The effect of maternal supine position on umbilical and cerebral blood flow indices. Eur J Obstet Gynecol Reprod Biol. 2014;175(1):112-114. doi:10.1016/j.ejogrb.2013.12.043

12. Essa RM, Hafez SK. Effect of different positions of pregnant women on their comfort and fetal cardiotocographic patterns during Non Stress test. Int J Res Heal Sci Nurs. 2018;4(2):1-24. https://gnpublication.org/index.php/hsn/article/view/257/. Accessed December 18, 2020.

13. American College of Obstetricians and Gynecologists (ACOG). Practice bulletin No. 145: Antepartum fetal surveillance. Obstet Gynecol. 2014;124(1):182-192. doi:10.1097/01.AOG.0000451759.90082.7b

14. Nathan EB, Haberman S, Burgess T, Minkoff $H$. The relationship of maternal position to the results of brief nonstress tests: A randomized clinical trial. Am J Obstet Gynecol. 2000;182(5):1070-1072. doi:10.1067/mob.2000.105443
15. Mehta CR, Patel NR. A hybrid algorithm for Fisher's exact test in unordered rxc contingency tables. Commun Stat Theory Methods. 1986;15(2):387-403. doi:10.1080/03610928608829128

16. Ibrahim HA, Elgzar WT, Saied EAR. The effect of different positions during Non-stress test on maternal hemodynamic parameters, satisfaction, and fetal cardiotocographic patterns. Afr J Reprod Health. 2021;25(1):81-89. doi:10.29063/ajrh2021/v25i1.10

17. Kıratlı D, Yavan T, Karaşahin KE, Yenen MC. The effect of different maternal positions on reactivity of the nonstress test, maternal blood pressure and heart rate. Journal of Dr Behcet $\mathrm{Uz}$ Childrens Hospital. 2018;8(2):101-108. doi:10.5222/buchd.2018.101

18. Kaur VS, Saha PK. A comparative study to assess the effect of different maternal position on reactivity and time consumption for nonstress test. Nurs Midwifery Res J. 2015;11(4):145-152. doi:10.33698/ NRF0193

19. Gorler A, Rani J, Kannan M. Correlation of maternal positions on maternal and fetal parameters during non-stress test among antenatal mothers at svmch\& rc, Puducherry. TNNMC J Obstet Gynaecol Nurs. 2021;9(1):14-18. https://www.indianjournals.com/ijor.aspx?target= ijor:tnnmcjogn\&volume $=9$ \&issue $=1 \&$ article $=003 /$. Accessed January 16, 2021.

20. Lekshmi S, Annie Annal M, Lavanya S. Effects of different maternal positions on maternal parameters and fetal heart rate among antenatal mothers during non-stress test. Pondicherry J Nurs. 2017;11(2): 13-16. https://pjn.sbvjournals.com/doi/PJN/pdf/10.5005/pjn-11-2-13. Accessed December 18, 2020.

21. EL Sayed HA, Mohamady SH. Effects of different maternal positions during non-stress test on maternofetal physiological parameters. Tanta Sci Nurs J. 2016;10(1):116-131. doi:10.21608/TSNJ.2016.71197

22. Siby R, Vinsi MS. Relation of semi-Fowler's position and supine position on comfort level of antenatal mothers during non-stress test. Int J Health Sci Res. 2019;9(7):115-120. https://www.ijhsr.org/IJHSR Vol.9_Issue.7_July2019/18.pdf. Accessed December 19, 2020. 